others, where the use of an actual cautery was productive of rapid and beneficiai results. Far be it from me to assume that any of the diseases, which apparently were subdued by its influence, would not have terminated in a manner equally favourable as if it had not been applied. Yet, seeing how fatally destructive such diseases frequently prove, and when so proving, how speedily the life is destroyed-knowing, also, that in every similar affection how anxious medical men are to produce a severe counter-irritation, from experience of its paramount importanceI felt justified in resorting to means which have hitherto been rarely employed, and of whose powerful influence we have little account, except in some isolated cases that have appeared in medical periodicals.

\section{CASE OF RECOVERY}

\section{FROM}

TAKING 'TWO DRACHMS OF ARSENIC.

By Jonathan Toogood, Esq.

W. R., aged 17, swallowed two drachms of arsenic, which he coarsely bruised with the end of a bottle at nine, p.m., on the $2 \mathrm{~d}$ of June, 1817, with a view to self-destruction. He repented, and made it known a quarter of an hour afterwards. Six grains of emetic tartar were immediately given and quickly repeated. Vomiting was soon excited, and briskly kept up, by copious draughts of warm water for two hours. Nothing was retained on the stomach during the night, and he complained of constant and severe pain in the stomach and bowels. He passed the night without rest, and on the following morning he complained still of great pain in his stomach and bowels, was very hot, with a frequent pulse and flushed countenance. He was copiously bled, and his bowels were relieved by injections, but nothing could be retained on the stomach until the erening after the application of a blister. Effervescing medicines, with opium, were then kept with difficulty, but he was not so much relieved until the fourth to make his recovery certain.

Bridgewater, December, 1841.

\section{ON QUACK COMPOSITIONS AND}

\section{PATENT MEDICINES.}

\author{
By JoH FosBRoke, M. D.
}

"Quackery has increased, is increasing, and must be diminished."-Bedpoes.

LOur correspondent's zeal in the good cause occasionally leads him away from the subject which he is discussting. We have, therefore, taken the liberty of pruning his article of some of its luxuriant offshoots.-Ens.]

Nothing that we have advanced concerning quacks and quackery, however comprehensive or forcible, can be complete, without a general overhauling of quack and patent medicines, which are great practical evils. Quackery, like sin, is very ancient. In the reign of the Emperor Valentinian, the medical practitioners of Rome, who were chiefly quacks, made laws to prevent the recovery of exacting and exorbitant charges and demands, particularly in the sale of secret compositions, which had prevailed in the empire. Circumstances in England and France are now precisely the same as formerly in Rome.
Mr. William Chamberlayne, in the beginning of this century, was a surgeon-apothecary at Clerkenwell, and the quaint and shrewd writer of Tyro Medicus, upon "The Duties of Medical Apprenticeship." About forty years ago he adverted to the mischief produced by the astonishing increase of the sale of patent and other empiric medicines; and, to show how much more the use of these injurious compositions prevailed in South than in North Britain, he observed, that the net amount, in one year, was not far short of $£ 14,000$ annually in stamp-duty, upon an augmenting sale of quack medicines and other injurious compositions, while in North Britain it returned not more than $£ 50$ per annum; and these exclusive of the duty on advertisements for the same.' -(London Medical and Physical Journal, 1801.)

Is this topographical difference owing to the greater proportion of sickness in the south, or to a greater degree of popular folly and credulity in the south than in the north? 'The people of the West of England, even to the east shore of the Severn, have been notorious, from Joln Wesley's time, for the love of quackery.

Dr. Cowan, of Reading, has rendercd good service to the profession and the anti-quackery cause, by his very able and efficient Reports on Quackery.-(Vol. viii., Transactions of the Provincial Medical and Surgical Association, p. 25., \&c.)

"The interests of government," he observes, "in empiricism were also, for the first time, accurately investigated, and it was shown, from unquestionable authority, that the revenue from quackery is less than $£ 50,000$ a year!!!" He then argues, that the great amount of the government profits is not one of the most tenable and practical objections urged by the opponents to all active measures. The obstacle of amount can no longer be regarded as insuperable or formidable.

"No efforts have yet been made to prevent, or even to curtail, the irresponsible and indiscriminate circulation of medicines; but that, by the stamp and patent regulations, this glaring abuse is legalised and encouraged; and, from the unequalled facilities which now exist for advertising, an injury upon the public health is inflicted, far greater than could ever be the case from the strictly personal, though unqualified, practice of physic." "The greatest, if not the most serious, obstacle to the procuring of the abolition of the patent medicines, at least in their present unrestricted form, is THE INERTNESS AND APATHY OF THE MEDICAL PROFESSION!!!!"-p. 78.

So it appears by Dr. Cowan's statement, compared with Mr. Chamberlayne's, that the sale of quack and patent medicines has increased, in nineteen years, full from $£] 4,000$ to $£ 50,000$ per annum, or by 3 and 1-8th.

Dr. Cowan has endeavoured, also, to form an estimate of the expenditure of the public in quack nostrums, and conceives it to be very high. He says that the increased sale may be deduced from taking an average of nearly five hundred stamped medicines, allowing for the greater numerical sale of the lowerpriced articles, and the multiplication of the sum so obtained by the annual number of stamps. Its accuracy is also confirmed by knowing the average value of the stamps, which clearly indicates the relative quantities sold of the cheaper and more expensive articles. Dr. Davies, of Presteign, says, "A town with a population of from 2,000 to 3,000 , having a weekly market, in a district wholly agricultural, sells at the least $£ 140$ worth of quack medicines yearly. This, I think, is $£ 40$ below the mark in many towns. I state the minimum."

Since the scarce corn and money year, 1838, a great number of the genteel, the middling, and the working classes, have left off applying to the physicians and general practitioners, and run to the shops for patent and quack medicines. Some druggists 